Service social

\title{
Culture : une notion polémique?
}

\section{Jean-Jacques Chalifoux}

Volume 42, numéro 1, 1993

\section{Culture et intervention}

URI : https://id.erudit.org/iderudit/706597ar

DOI : https://doi.org/10.7202/706597ar

Aller au sommaire du numéro

Éditeur(s)

École de service social de l'Université Laval

ISSN

1708-1734 (numérique)

Découvrir la revue

Citer cet article

Chalifoux, J.-J. (1993). Culture : une notion polémique? Service social, 42(1),

11-23. https://doi.org/10.7202/706597ar

\section{Résumé de l'article}

La notion de culture est paradoxale, car elle renvoie à la fois à un concept, la culture, et à des choses, les cultures. L'utilisation de la notion de culture n'est pas neutre, elle s'est développée dans un contexte sociopolitique polémique, tout comme son usage actuel. Appliquée à l'hétérogénéité ethnique, la perspective culturaliste peut être réductionniste si elle ne tient pas compte adéquatement des contextes sociaux plus larges. d'utilisation que vous pouvez consulter en ligne.

https://apropos.erudit.org/fr/usagers/politique-dutilisation/ 


\section{A $R$ R $T$ I I C L L E S}

\section{Culture: une notion polémique?}

Jean-Jacques CHALIFOUX

Professeur

Département d'anthropologie

Université Laval

\section{INTRODUCTION}

La notion anthropologique de culture a connu un développement contradictoire et conflictuel. D'une part, le savoir considérable que la définition d'un domaine "culturaliste » a permis d'accumuler n'a pas entrainé une contrepartie théorique équivalente. La notion de culture est demeurée plutôt imprécise, intuitive et, en théorie, correspond à un pré-concept soumis à de multiples critiques. D'autre part, cette notion a une histoire qui émerge des rapports sociaux où les différences de pouvoir et de rapport de force sont déterminantes.

La diffusion interdisciplinaire d'une telle notion peut avoir des effets réducteurs, surtout lorsque sa pertinence est préférablement évaluée de façon essentiellement positiviste par la recherche de moyens pour décrire et mesurer d'une manière supposément "scientifique» le monde social afin de le comprendre et de le modifier. Signe de l'incontournable nécessité d'élaborer de nouveaux moyens de communication dans le contexte de la mondialisation et signe de l'exigence industrielle moderne d'une nouvelle forme de cohésion sociale, I'usage utilitaire de la notion de culture vise-t-il autre chose qu'à définir des territoires d'experts en relations interculturelles?

Cette question est d'autant plus pertinente que la notion de culture apparaît de plus en plus comme un illusoire terrain neutre. Chaque catégorie 
sociale, chaque groupe social posséderait une différence culturelle qu'il suffit de comprendre et de relativiser pour agir de façon cohérente afin de résoudre les problèmes sociaux.

Le choix pragmatique d'une approche n'implique pas nécessairement une décision rationnelle du chercheur qui aurait pondéré sa valeur scientifique relative. La perspective choisie est généralement un effet du milieu social et intellectuel où il baigne, de la tradition qu'on lui a enseignée. Seule une réflexion théorique peut permettre de développer un point de vue cohérent et réfléchi. C'est dans le but d'engager de façon préliminaire cette réflexion critique qu'il faut lire ce petit texte qui n'a pour prétention que de présenter quelques éléments critiques de la définition ainsi que la portée sociale de la notion de culture.

Dans un premier temps, nous ferons un rapide survol des principales perspectives anthropologiques sur la culture afin d'indiquer quel est l'éventail des choix d'outils théoriques qui se présentent.

Dans un second temps, quelques éléments historiques auront pour but de montrer que la notion de culture est paradoxale et qu'elle a une valeur sociale idéologique. En effet, nous verrons d'une part qu'en anthropologie la notion de culture est à la fois un concept et une chose. Ce double sens engendre une certaine confusion et quelques débats théoriques visant à définir un niveau d'analyse pertinent. Enfin, nous indiquerons comment l'application naïve de la perspective culturaliste à l'hétérogénéité ethnique peut être réductionniste si elle ne tient pas compte des contextes sociaux plus larges.

\section{UN BREF SURVOL DES THÉORIES DE LA CULTURE}

La plupart des ouvrages d'histoire de la pensée anthropologique proposent divers survols des polémiques théoriques (Kroeber et Cluckhohn, 1952; Schulte-Tenckhoff, 1985). Pour donner une idée générale du contenu de la boîte à outils culturels modernes, une simple liste des perspectives débattues, quoique imprécise et non exhaustive, devrait suffire:

1. La culture considérée métaphoriquement comme un mode d'adaptation aux conditions de vie. Par exemple, l'évolutionnisme et les explications de l'écologie culturelle, du matérialisme culturel, de la sociobiologie et de l'éthologie humaine.

2. La culture vue comme une idéologie. Par exemple, la théorie des conflits marxiste, néo-marxiste et fonctionnaliste ou la théorie féministe.

3. La culture comme système de valeurs et de normes sous-jacent à l'action sociale. Par exemple, la théorie de I'action sociale selon Weber et Parsons ou la théorie de la sociologie critique ou la théorie de l'échange. 
4. La culture comme système selon le structuro-fonctionnalisme durkheimien ou la théorie des systèmes, I'approche cybernétique, I'analyse des réseaux, la théorie des jeux.

5. La culture comme événement unique et historique selon le particularisme historique, le diffusionnisme, I'ethnohistoire.

6. La culture comme structure cognitive de I'anthropologie psychologique, de l'école culture et personnalité, de l'anthropologie cognitive, de la nouvelle ethnographie et de l'anthropologie symbolique ou de l'interaction symbolique.

7. La culture comme inconscient, précondition à la pensée du structuralisme selon Lévi-Strauss ou selon la perspective de l'anthropologie dialectique ou de l'ethnométhodologie.

Il apparaît évident qu'une réflexion sur la culture ne peut se contenter d'a priori naïfs qui feraient l'économie des différents regards qu'engendrent ces multiples orientations théoriques. Leur mise en perspective est également devenue une nécessité méthodologique, car chacune privilégie une dimension particulière au détriment des autres en fonction des contextes dans lesquels ont travaillé les chercheurs.

Le problème majeur qui limite la possibilité d'une critique globale de la notion de culture est la diversité des acceptions qui rendent l'entreprise difficile (Fardon, 1992). Cependant, une réflexion de base sur le concept de culture dans la théorie anthropologique culturaliste demeure un préalable.

\section{LA CULTURE: UNE NOTION PARADOXALE ET IDÉOLOGIQUE?}

En anthropologie, la notion de culture est définie de façon paradoxale. D'une part, elle a une signification singulière: la culture est cette chose universelle chez les humains qui diffère du biologique, elle est le propre de I' " Homme» au sens anthropologique du terme. D'autre part, elle a une signification plurielle: il existe une multitude de cultures distinctes composées d'éléments complexes correspondant aux différentes sociétés.

Historiquement, ce double sens de la notion de culture résulte d'une polémique idéologique franco-allemande qui s'est traduite par I'opposition entre les valeurs universelles de la "Civilisation» et celles, plus particularistes, de la «Kultur» (Finkielkraut, 1987). Les penseurs français privilégiaient la notion de civilisation qui véhiculait les valeurs de savoirvivre et d'humanisme de l'aristocratie européenne: politesse, bienséance, courtoisie. La bourgeoisie révolutionnaire lui a ajouté les valeurs de vertu, droit et liberté. Ainsi, la personne civilisée était cultivée, au sens métaphorique de quelqu'un qui cultive les choses de l'esprit comme on cultive un jardin. 
Le développement économique des nations française et anglaise encourageait la propagation de la "civilisation » aux autres peuples du monde dont les différences s'estomperaient devant leur destin commun. La civilisation humanise la brute qui se cache en l'homme et lui propose des valeurs esthétiques et une morale universelle.

La noblesse allemande était entièrement acquise à cette idée de "civilisation universelle» qui correspondait, chez Kant en particulier, à la notion de Kultur. Cependant, dans un pays politiquement éclaté et sans État national comme l'était l'Allemagne au $18^{\mathrm{e}}$ siècle, le peuple ou Volk devint le référent unificateur de la bourgeoisie nationaliste allemande infériosée par ses voisins. Ainsi, chez le philosophe Herder la notion de Kultur prenait un sens restreint à l'ethnie et faisait ressortir les valeurs du peuple allemand. Cette notion mettait l'accent sur la tradition populaire et sa littérature romantique, elle exaltait l'amour de la nature et la spontanéité de l'expression des émotions en opposition aux manières superficielles et importées des nobles.

Au $19^{e}$ siècle, en Angleterre, I'anthropologue E.B. Tylor (1874) emprunte le terme Kultur aux Allemands et lui donne un sens à la fois particulier et universel qui devient le référent central de l'anthropologie culturelle:

La Culture ou Civilisation entendue dans son sens ethnographique étendu est cet ensemble complexe qui comprend les connaissances, les croyances, l'art, le droit, la morale, les coutumes et toutes habitudes et aptitudes qu'acquiert l'homme en tant que membre d'une société.

Cette définition de la culture n'est pas neutre, elle s'élabore dans le contexte des conflits de pouvoir entre groupes inégaux au sein du colonialisme, de l'esclavage, de la décolonisation et du développement des droits humains. Tylor et ses contemporains ne doutaient pas de la supériorité des sociétés européennes et de la leur en particulier.

Cependant, pour l'anthropologie naissante, cette approche dite culturaliste avait de nombreux mérites. D'une part, en introduisant l'idée que la culture ne se confondait pas avec l'existence d'une élite, elle pouvait caractériser la culture populaire de tous les peuples du monde et, en particulier, les sociétés de parenté communautaire rencontrées par les anthropologues. D'autre part, comme tous les humains partagent cette caractéristique qu'est la culture, ils sont comparables sur ce point.

Certaines méthodes de comparaison mirent l'accent sur l'aspect universel de la culture et découvrirent que les sociétés s'ordonnaient selon des degrés de développement culturel inégaux. $S^{\prime}$ inspirant de Spencer et Darwin, des anthropologues expliquèrent ces écarts par des raisons géographiques et historiques, certaines sociétés étant restées bloquées aux premières étapes sauvages et barbares de l'évolution humaine. Cette méthode apparut rapide- 
ment pour ce qu'elle était: une approche superficielle fondée sur des préjugés ethnocentriques.

Cette critique a mis en valeur la nécessité d'aborder les différences culturelles d'une façon globale dont la condition méthodologique préalable est de considérer chaque culture selon ses propres termes, c'est-à-dire selon ses valeurs et ses représentations. Cette approche relativiste repose sur le désir et la volonté d'acquérir une connaissance interculturelle qui permet de se décentrer pour adopter le point de vue de l'autre, afin de construire des ponts de compréhension mutuelle. Cela permet au relativisme culturel de postuler à la fois que chaque culture est unique et que, pour comprendre les cultures, il est possible d'établir un certain degré de similarité au connu.

La définition de la culture comme un tout «superorganique » avait pour objectif méthodologique de permettre cette comparaison qui se heurtait à plusieurs obstacles idéologiques difficiles à surmonter, le principal étant le lien causal postulé entre «la race, la langue et la culture». Tant que les différences culturelles humaines s'expliquaient par la seule hypothèse des différences raciales et linguistiques, les comparaisons demeuraient impossibles, puisque que les différences étaient incommensurables. Le postulat de la discontinuité entre la race, la langue et la culture a permis de dépasser les abus de l'idéologie raciste et de promouvoir l'idée de l'unité psychique de l'humanité. Ainsi, l'étude comparative des cultures devenait possible, car celles-ci échappaient au déterminisme racial auquel se réduisait autrement I'anthropologie.

En situant la culture comme ensemble, la définition de Tylor se rapproche de l'idée moderne de système. Elle permet de définir les contextes des actions humaines de façon cohérente en partant du postulat que la vie quotidienne forme un tout organisé qui permet aux personnes de prévoir les comportements les uns des autres. L'organisation des cultures suit donc une logique d'ensemble qui leur donne une certaine cohérence malgré les multiples variations et disparités des conduites sociales de la vie quotidienne. Cette vision de la culture comme totalité a eu plusieurs avantages scientifiques, ne serait-ce que l'idée de chercher la causalité dans les liens qui unissent le particulier au tout.

En mettant l'accent sur l'apprentissage, cette définition souligne que la discontinuité de l'organique et du culturel implique que la culture est acquise et non pas innée. Le culturalisme repose donc sur une théorie de l'impact de la culture sur l'individu. Celui-ci peut même apparaître comme la créature de la culture. Plusieurs auteurs (Benedict, Herskovitz, Kardiner, Linton) ont pensé que la culture était, en tant que réalité externe aux personnes, déterminante de l'expérience individuelle.

La transmission culturelle ou enculturation se fait par la communication entre individus de différentes générations. Les nouveaux membres d'un 
groupe social apprennent les «traditions», I' « héritage culturel» ou les " coutumes» au contact des plus anciens.

Considérée sous cet angle, la totalité culturelle peut être appréhendée indirectement à travers les idées qui filtrent les actions humaines. Ces idées abstraites et générales sont constituantes des institutions sociales et forment la base de la structure sociale. La notion de culture prend alors un sens restreint, distinct des dimensions psychologiques et sociales de la vie collective. Elle renvoie à la vision du monde, aux liens fonctionnels qui lient les symboles, les valeurs et la société dont ils sont les reflets ou l'expression. Les personnes perçoivent un sens, une signification au réel parce que celui-ci est filtré par la culture qui lui attribue une valeur symbolique.

\section{la CUlture CONTRE la Société}

La perspective culturaliste se définit comme une antithèse de l'ethnocentrisme et du racisme et, en tant que telle, elle est la source d'une importante critique sociale. Cependant, d'une part, le réductionnisme et la réification des valeurs que véhicule le culturalisme et, d'autre part, l'adéquation entre culture et ethnicité en diminuent beaucoup la portée sociale. En effet, l'importance de l'intervention de l'État et l'impact des structures sociales complexes obligent à reconsidérer la fonction globalisante et intégratrice traditionnellement associée à la culture. II ne s'agit pas ici de remplacer le concept de culture par celui de société, mais de souligner l'importance de l'analyse contextuelle (voir Strathern, 1987).

\section{CULTURE ET VALEURS}

La réduction de la culture aux valeurs s'est particulièrement développée sous I'influence de la pensée fonctionnaliste, en particulier celle de T. Parsons (1968).

L'approche culturaliste a tendance à voir une correspondance univoque entre les valeurs et les institutions sociales et à minimiser l'impact de l'hétérogénéité sociale. On peut facilement reconnaître qu'il n'y a pas qu'un seul système de valeurs partagé par les membres d'une société ou d'un groupe, mais plusieurs qui se contredisent, s'opposent et renferment chacun une multitude d'interprétations variables en fonction des positions sociales tant d'âge, de sexe que de statut social, tant des acteurs que des observateurs. Ces sous-groupes peuvent contester, critiquer, redéfinir ou manipuler les significations culturelles dans des luttes parfois récupérées par la dynamique sociale, mais engendrant parfois, également, des transformations radicales. 
On n'a qu'à s'interroger sur l'actualité en Chine contemporaine où le socialisme à économie de marché semble se nourrir du potentiel créateur de rapports polémiques entre l'État et le Capital.

Cette hétérogénéité sociale n'apparaît que si la vision holiste de la culture est confrontée à celles des individus qui manifestent des interprétations différentes en tant que membres de groupes d'intérêts opposés au sein de la même société. Par exemple, Erikson (1993) compare les cultures nationales élitistes et populaires de Trinidad et de l'île Maurice et montre que les valeurs associées à la réputation et à la respectabilité forment deux ensembles opposés et contradictoires. II note que cette ambiguiité philosophique n'a pas à être résolue, car dans la vie quotidienne ces valeurs sont complémentaires. L'individu peut choisir l'une ou l'autre en fonction du contexte et de la situation qu'il vit. Ainsi, pour plusieurs personnes, la pluralité des partenaires sexuels n'apparaît pas contradictoire avec la foi religieuse, les deux types de valeurs jouant sur des plans différents. De ce point de vue, la culture apparaît telle une propriété ambiguë d'une série de relations et de processus sociaux et non comme une propriété statique de la société.

Il faut souligner également que les valeurs ne prennent leur sens que dans le contexte plus vaste de la sémiotique de la culture (Umiker-Sebeok, 1977). Par exemple, le domaine culturel des représentations du corps humain et de la nature matérielle et spirituelle de la personne humaine ne s'analyse pas seulement à l'aide du concept de valeur, mais également en tant que système de signes révélant une logique symbolique constituée de multiples métaphores utiles pour comprendre le monde. En effet, au cours d'une recherche chez des Amérindiens de Guyane en Amérique du Sud, j'ai observé I'existence d'un contraignant tabou interdisant les contacts directs et indirects des hommes avec les femmes menstruées. Une analyse naïve aurait pu se contenter de montrer que des valeurs négatives sont associées aux femmes et rater complètement la signification profonde des interdits qui s'expliquent par des métaphores concernant les rythmes de la vie et la société dans son ensemble.

\section{CULTURE ET ETHNICITÉ}

Le principal problème de l'approche culturaliste est la difficulté de définir les frontières sociales des cultures en tant qu'objets, de même que des groupes qui en sont porteurs. Le culturalisme transforme l'identification par les différences (nous nous définissons différents des autres) en différences par identification (eux, ils sont différents des autres). Cette démarche fait apparâ̂tre un monde composé de cultures qui ne se comparent que pour dévoiler leurs différences qui sont telles qu'elles apparaissent comme des univers clos (Dumont, 1978). 
L'approche culturaliste définit et classe les cultures comme autant de groupes ethniques différents. La notion culturaliste de l'ethnicité est essentialiste, elle repose sur l'idée qu'il s'agit d'un phénomène primordial, une sorte de seconde nature inhérente, inévitable, immuable et tenue pour acquise. On naît au sein d'un groupe ayant son histoire, son territoire, sa culture, sa langue, sa religion et sa psychologie particulière. Transmise de génération en génération, l'identité ethnique se confond avec l'identité culturelle. Cette conception de la culture synonyme d'ethnie fait partie des évidences à remettre en question.

Cette notion de culture apparaît trop restreinte lorsqu'elle est réduite aux particularités d'une seule catégorie sociale sans tenir compte du contexte plus large dans lequel elle se situe. Les cultures minoritaires sont souvent celles de la pauvreté définie au sein des luttes de pouvoir et de domination. Pour critiquer la vision élitiste de la culture, la fameuse "École de Chicago», par exemple, n'avait eu qu'à se pencher sur le développement des minorités dans cette ville pour découvrir que la culture élitiste blanche anglo-saxonne n'intégrait pas les nombreuses minorités ethniques. Celles-ci devinrent des sous-unités culturelles (subcultures) ayant chacune ses systèmes de socialisation et de valeurs culturelles. Cependant, ces unités sont loin d'être fermées sur elles-mêmes : elles s'intègrent à des ensembles plus vastes, régionaux, nationaux et même mondiaux où se partagent aujourd'hui des aspects de la culture internationale. La culture ne peut donc être réduite à ses aspects de traditions locales, le système mondial la façonnant constamment.

$C^{\prime}$ est ce que Linton (1968) avait fait valoir lorsqu'il a ironiquement décrit la vie quotidienne d'un Américain se croyant $100 \%$ authentique, alors que tous ses traits culturels avaient été empruntés à une multitude de lieux et de temps. Le processus d'identification ethnique ou ethnicisation ne peut donc renvoyer à l'ensemble de la culture des groupes classés, car les divers éléments ne connaissent pas de frontières et se distribuent d'un groupe à l'autre. Les emprunts et les fusions culturelles sont constitutifs de l'histoire de I'humanité et il ne peut exister aucune réelle frontière étanche et absolue entre les groupes humains. Les frontières entre cultures et sociétés différentes sont donc relativement floues: elles se ressemblent toutes par certains côtés et diffèrent toutes par d'autres aspects.

Une « ethno-culture » ne peut donc être définie qu'à la condition d'être «prélevée arbitrairement » du tissu social dans lequel elle s'insère (Amselle, 1990: 55). La détermination et la comparaison des cultures sont par conséquent relatives et dépendantes de l'échelle choisie, car les différences culturelles sont constituées d'écarts plus ou moins grands (Lévi-Strauss, 1952 et 1971). S'agit-il de continents, de pays, de régions, de milieux urbains ou ruraux, de milieux de travail, de groupes d'âge ou de genre, etc. ? Par exemple, il est possible que le Japon et le Québec se différencient sur la place 
culturelle attribuée au travail par plusieurs personnes: au Japon, le travail semble le but de la vie, alors qu'au Québec le travail semble un moyen pour vivre... Ce type d'écarts entre traits culturels fonde la perception arbitraire de la séparation et des frontières entre les groupes. Différente de la perspective statique du culturalisme, la vision constructiviste de la culture et de l'ethnicité peut mieux rendre compte des observations qui indiquent que les caractéristiques définissant I'identité ethnique peuvent changer et être l'objet de redéfinitions.

Ainsi, pour Barth (1969), I'ethnicité est plus spécifique que la culture ; $c^{\prime}$ est un processus d'organisation sociale où un groupe utilise des traits culturels pour se distinguer des autres. L'identité ethnique apparaît alors comme le résultat de l'interaction sociale: une communauté isolée ne se définit pas en tant qu'ethnie, mais plus les interactions avec d'autres communautés culturelles distinctes sont importantes, plus les individus accentuent leurs différences ethniques à l'aide d'emblèmes marquant la frontière entre eux. Des caractéristiques sont sélectionnées de préférence à d'autres pour devenir des marqueurs ethniques, des traits qui permettent de reconnaître la spécificité d'un groupe en comparaison avec d'autres groupes similaires.

Les critères emblématiques d'un groupe peuvent être choisis parmi plusieurs possibilités: il peut s'agir d'objets comme des vêtements, d'idées comme la valeur attribuée à I'hospitalité ou à la religion ou bien de références au passé ou à la généalogie ou à l'organisation sociale (la polygamie caractérisant les Musulmans, par exemple, n'est pas une fiction imaginaire même si elle est souvent abusivement généralisée).

La redéfinition ethnique de caractéristiques culturelles est une construction en écarts socialement significatifs. L'inverse peut également être vrai : des aspects d'une culture peuvent être inventés ou modifiés pour mieux se distinguer des autres. De complexes systèmes de parenté où les hommes et les femmes épousent plusieurs conjoints sans divorcer ont pu s'élaborer au centre du Nigéria par un processus de permutation de règles de mariages distinguant, en plus de la langue et d'autres permutations culturelles, chacune des sociétés (Chalifoux, 1982).

Parmi toutes les caractéristiques sociales et culturelles observables au Québec, seules certaines caractéristiques particulières servent à définir les groupes ethniques. Pensons, pour illustrer brièvement, aux catégories englobantes qui opposent l'Occident et le Tiers-Monde, les Chrétiens, les Juifs et les Musulmans, les Blancs et les Noirs, les Francophones et les Allophones, les Hommes et les Femmes et aux multiples façons de combiner et de hiérarchiser ces écarts en fonction de la distance sociale que I'on veut établir. Peut-on faire partie du même groupe linguistique et être de religions différentes? Quels critères seront prépondérants, quel contexte favorise l'usage de l'un ou de l'autre? 
Les individus comme les collectivités peuvent manipuler ces systèmes identitaires et se resituer eux-mêmes et resituer les autres sur l'échiquier des relations interculturelles. Les minorités ethniques, par exemple, apparaissent simultanément membres et non membres, « insiders» et «outsiders ». Leur statut social est par définition ambigu et l'individu doit s'ajuster à plusieurs identités et images de soi sans qu'aucun pattern culturel unique offre réellement de solutions philosophiques sécurisantes. Les cultures proposent des codes pour classer ces expériences et leur attribuer des significations. Dans tous les cas, ces codes sont flexibles, car ils varient selon les circonstances historiques, sociales et politiques. O. Patterson (1978), par exemple, a montré comment des stratégies économiques favorisent la mise en valeur de l'identité chinoise à la Jamaïque, alors qu'elles ont produit l'inverse en Guyane.

Les définitions et les classifications ethniques peuvent être l'objet d'une lutte politique entre le pouvoir des classificateurs et la situation sociale de ceux qui sont classés. De ce point de vue, un groupe social ne devient « ethno-culture » que parce que certains acteurs sociaux (migrants, intellectuels urbains, intervenants d'organisations et de l'État) jouent le rôle de définisseurs et réussissent à le propulser sur l'avant-scène sociale et politique. Dans ce contexte, l'utilisation stratégique du relativisme culturel peut-il ne pas être ethnocentrique lorsqu'il devient une méthode d'approche pour faciliter l'intégration sociale à un meilleur coût dans le cadre de la gestion étatique des différences humaines?

Cette dynamique $n^{\prime}$ implique pas seulement un mouvement de la majorité à la minorité, mais l'inverse également. Les membres individuels des cultures dominantes peuvent devenir eux-mêmes des emblèmes ethniques. Ils pourront être interprétés différemment par les membres des groupes minoritaires selon le contexte: soit de façon positive, pour établir des alliances à l'aide, par exemple, d'idéologies assimilationnistes, ou de façon péjorative, dans un contexte de rivalité à l'aide, par exemple, d'idéologies tiersmondistes critiques de la société occidentale.

Quel est le meilleur statut social pour un immigrant? Est-ce celui de sous-prolétaire marginal ou celui de membre d'une minorité ethnique? Dans le premier cas, son identification sociale place l'immigrant au bas de l'échelle sociale; dans l'autre cas, celui-ci fait partie d'un groupe pouvant revendiquer le droit à l'égalité culturelle. Roosen (1989) pense que cette stratégie de revendication sociale fut rendue possible par l'acceptation dans les pays démocratiques de l'idée du relativisme culturel et par la prise de conscience des dangers de l'ethnocentrisme excédé et des génocides nazis. De plus, I'importance attribuée au fait ethnique dans un pays comme le Canada valorise ce type de stratégie politique revendicatrice. Par ailleurs, Glazer et Monihan (1975) ont conclu que l'intervention de l'État dans les affaires sociales a encouragé l'émergence de groupes de pression où l'orientation ethnique a une efficacité stratégique. 
Le contexte institutionnel et la structure sociale inégalitaire sont évidemment déterminants des formes d'interaction. Par exemple, des enclaves ethniques peuvent naître de la discrimination sociale (refus d'appliquer des droits équivalents à diverses catégories de personnes) par des membres de groupes dominants qui disposent des moyens économiques, politiques et autres de s'assurer une influence déterminante sur des groupes ethniques et de maintenir une ségrégation sociale et spatiale.

La discrimination peut être individuelle comme dans le cas où une personne déteste toutes les personnes qui sont différentes, quand la peur, la colère, la méfiance s'insèrent a priori entre deux personnes ethniquement différenciées. La discrimination peut être plus subtile, comme quand elle est institutionnelle et résulte du conformisme des règles sociales qui empêchent la participation de membres de minorités. Ainsi, les femmes ne représentent qu'un faible pourcentage des cadres supérieurs, principalement parce qu'elles n'ont pas depuis longtemps la possibilité d'accéder aux moyens nécessaires pour investir ces lieux de pouvoir. De même, la discrimination raciale directe n'explique pas pourquoi il y a peu de Noirs au sein de la direction des grandes entreprises. Le manque de moyens pour obtenir l'éducation nécessaire et les réseaux de connaissances utiles en est la cause profonde.

\section{CONCLUSION}

La notion de culture a été définie comme un univers clos, utile pour décrire et expliquer les écarts par leurs contenus objectifs, c'est-à-dire par des critères renvoyant à des faits différentiels observables dont le répertoire est pratiquement illimité: cuisine, pratique religieuse, etc. Ces descriptions holistes des cultures sont le résultat d'un travail de synthèse et de construction du chercheur qui leur donne ainsi une substance particulière. Cependant, les cultures décrites ne deviennent pas des choses, car elles ne sont pas le point de départ de l'analyse, mais son résultat.

Nous avons vu que dans le contexte colonial de son origine, I'anthropologie fut façonnée par les luttes entre les racistes et les antiracistes et entre les relativistes et les universalistes. On pourrait démontrer que le relativisme culturel même fut développé dans le contexte des luttes amérindiennes contre I'intervention administrative en Amérique ou que la guerre du Vietnam, par exemple, a permis le développement de perspectives critiques et d'inspiration marxiste. De même, les conflits contemporains entre les genres introduisent des perspectives féministes, tandis que la mondialisation des rapports sociaux influe sur les approches dites postmodernes. II n'y a donc pas d'évolution du savoir anthropologique, mais seulement des savoirs plus ou moins pertinents selon les contextes sociopolitiques. 
Les notions de culture et d'ethnicité furent par ailleurs utilisées pour définir et classer les différences humaines tant par les chercheurs que par les groupes et les individus qui revendiquent une reconnaissance identitaire. Ces notions sont-elles en train de devenir ce territoire d'experts, ce lieu commun où se rencontrent les intérêts partagés par les divers spécialistes, les chercheurs de l'interculturel ainsi que les élites des groupes minoritaires et des soit-disant "communautés culturelles »? En effet, bien que les uns s'opposent aux autres, ils partagent la même arène sociopolitique et, de ce fait, il peut être de leur intérêt commun que le débat se prolonge.

Il est à espérer que les éléments de réflexion qui viennent d'être esquissés inciteront à une prudence élémentaire devant ce consensus sur une notion dont la popularité peut résulter en une sorte d'illusion qui évacuerait les enjeux de la démocratisation sociale.

\section{Références bibliographiques}

AmSELle, J. L. (1990). Logiques métisses. Anthropologie de l'identité en Afrique et ailleurs. Paris: Bibliothèque scientifique Payot. $250 \mathrm{p}$.

BARTH, F. (ed.) (1969). «Introduction», dans Ethnic Groups and Boundaries. London: George Allen and Unwin, p. 1-38.

CHALIFOUX, J. J. (1982). «Ethnicité et culture chez les Javanais de Guyane et les Abisi du Nigéria », Pluriel, n $32: 53-57$.

Delacampagne, C. (1983). L'invention du racisme. Antiquité et Moyen-Âge. Paris : Fayard.

DuMONT, L. (1978). «La communauté anthropologique et l'idéologie», L'Homme, $\mathrm{n}^{\circ} 3-4: 83-110$.

ERIKSON, T. H. (1993). «Formal and informal nationalism », Ethnic and Racial Studies, vol. 16, $\mathrm{n}^{\circ} 1$, janvier: 1-25.

FARDON, R. (1992). "Postmodern Anthropology? Or, an Anthropology of Postmodernity? », dans J. Doherty, E. Graham et M. Malek, Postmodernism and the Social Sciences. New York: St. Martin's Press, p. 24-38.

FINKIELKRAUT, A. (1987). La défaite de la pensée. Paris: Gallimard.

GLAZER, N. et D. MONIHAN (eds.) (1975). Ethnicity: Theory and Experience. Cambridge, MA: Harvard University Press.

KROEBer, A. et C. CluCKHOHN (1952). Culture, A Critical Review of Concepts and Definitions. New York : Vintage Books.

LÉVI-STRAUSS, C. (1952). Race et histoire. Paris: Gonthier.

LÉVI-STRAUSS, C., 1971 (1983). «Race et culture», dans Le Regard éloigné. Paris: Plon.

LINTON, R., 1968 (1936). De I'Homme. Paris: Minuit.

PARSONS, T. (1968). The Structure of Social Action, vol. I et II. Glencoe: The Free Press. 
PATterson, O. (1978). Ethnic Chauvinism: The Reactionary Impulse. New York: Stein and Day.

RoOSEN, E.E. (1989). Creating Ethnicity. The Process of Ethnogenesis. Newbury Park, CA : Frontiers of Anthropology, SAGE.

SCHULTE-TENCKHOFF, I. (1985). "La vue portée au loin. " Une histoire de la pensée anthropologique. Lausanne, Suisse : Éditions d'en bas, p. 223.

STRATHERN, M. (1987). "Out of context; the persuasive fictions of anthropology», Current Anthropology, vol. 28, no $3: 251-81$.

TYLOR, E.B. (1874). Primitive Culture. Boston: Estes and Lauriat. Cité dans Kroeber et Cluckhohn, 1952, p. 81.

UMIKER-SEBEOK, D.J. (1977). "Semiotics of Culture: Great Britain and North America », Annual Review of Anthropology, 6:121-35. 